Saudi Journal of Medicine

Abbreviated Key Title: Saudi J Med ISSN 2518-3389 (Print) |ISSN 2518-3397 (Online)

\title{
Deficiency of Antioxidant Vitamins and Some Hematological Indices of Pre-Eclamptic Subjects
}

\author{
Kani Y. A ${ }^{1 *}$, Muhammad $\mathrm{Y}^{2}$, Zainab I ${ }^{3}$, Zainab $\mathrm{AF}^{4}$, Rehinat $\mathrm{A}^{4}$, Saeed $\mathrm{S}^{5}$, Kani $\mathrm{MK}^{6}$, Muhd $\mathrm{BK}^{7}$ \\ ${ }^{1}$ College of Medicine and Health Sciences, Federal University Dutse, Dutse, Jigawa State, Nigeria \\ ${ }^{2}$ Department of Chemical Pathology, Rasheed Shekoni Specialist Hospital, Dutse, Nigeria \\ ${ }^{3}$ Department of Hematology and Blood Transfusion Rasheed Shekoni specialist Hospital, Dutse, Nigeria \\ ${ }^{4}$ Department of Obstetrics and Gynecology, Rasheed Shekoni Specialist Hospital, Dutse, Nigeria \\ ${ }^{5}$ Department of Hematology 44 Reference Hospital Kaduna, Sokoto Road, Badiko, Kaduna, Nigeria \\ ${ }^{6}$ Department of Hematology and Blood Transfusion, Federal Medical Centre Birnin Kudu, Birnin Kudu, Nigeria \\ ${ }^{7}$ Department of Biotechnology, Federal University Dutse PMB 7156, Nigeria
}

DOI: 1 10.36348/sjm.2020.v05i03.009 $\quad$ | Received: 12.02.2020 | Accepted: 19.02 .2020 | Published: 27.03 .2020

*Corresponding author: Kani Y. A

\section{Abstract}

Pre-eclampsia is an important clinical syndrome with an elevated blood pressure and marked proteinuria and may be associated with haemolysis, elevated liver enzymes and low platelets (HELLP) syndrome. Recently, oxidative stress is thought to play a role in the pathogenesis of pre-eclampsia. The current research consisted of 77 women with preeclampsia and 45 normotensive subjects attending Rasheed Shekoni specialist hospital and General hospital Dutse. Serum antioxidant vitamins A, C, E and some hematological indices were analyzed in both groups. Results revealed a statistical decrease $(\mathrm{p}<0.005)$ of vitamin A, C, E and platelet in pre-eclamptic compared to normotensive women. Antioxidant and platelet concentrate supplementation may supress the development of pre-eclampsia.

Keywords: Pre-eclampsia, Antioxidant vitamins, Oxidative stress, hematological parameters.

Copyright @ 2020: This is an open-access article distributed under the terms of the Creative Commons Attribution license which permits unrestricted use, distribution, and reproduction in any medium for non-commercial use (NonCommercial, or CC-BY-NC) provided the original author and source are credited.

\section{INTRODUCTION}

Pre-eclampsia is a clinical syndrome affecting about $7 \%$ of pregnant women characterized by hypertension and proteinuria at the second half of gestation [1, 2]. It is one of the leading causes of maternal morbidity and mortality [3, 4]. Pre-eclampsia can progress into an advanced clinical condition known as HELLP syndrome (hemolysis, elevated liver enzymes and low platelet counts) [5]. Roberts and Hubel [6] and Roberts and Escudero [7], both agreed that the placenta is central in the pathogenesis of preeclampsia due to the fact that removal of the placenta regresses pre-eclampsia. It is further noted that endothelial dysfunction observed in pre-eclamptic subjects may be due to release of some factors from the placenta $[8,9]$. Oxidative stress may be defined as the situation where by free radicals generation such as reactive oxygen and peroxides overwhelmed the antioxidant capacity in the body system [10]. It has been reported by Vanderlelie et al., [11] and Rayman [12], that all antioxidant enzymes were drastically reduced in women with pre-eclampsia. An increased mRNA gene expression of fetal hemoglobin $(\mathrm{HbF})$ and subsequent accumulation of the protein could play a key role in the pathological mechanisms in both placenta and maternal endothelium observed in preeclampsia leading to oxidative stress [13]. Recently, it has been suggested that oxidative stress may contribute to the development and advancement of preeclampsia due to damage of lipids, proteins and DNA from the blood and placenta [14, 15]. The present research aimed at reporting the serum levels of antioxidants and some hematological indices among pre-eclamptic subjects in Dutse metropolis Jigawa, Nigeria.

\section{MATERIALS AND METHODS}

Study Area: The study was conducted at Antenatal clinics of Rasheed Shekoni Specialist hospital and General Dutse both located in Dutse.

Study Design: The current research is an analytical case control study.

Study Population: The study consisted of 77 preeclamptic women attending antenatal clinic of either Rasheed Shekoni specialist hospital Dutse or General hospital Dutse. Pre eclampsia was diagnosed with blood pressure of $\geq 140 / 90 \mathrm{mmHg}$ at two different occasions 
with at least interval of 6hrs in the second half of gestation.

Exclusion and Inclusion Criteria: Participants with history of chronic hypertension, chronic renal failure, diabetes, liver disorders, multiple gestations or with any chronic medical condition were excluded.

Blood specimen: Five (5) mills of blood were collected from the medial cubital vein and delivered into EDTA and plain container for analysis of hematological indices and serum antioxidant vitamins.
Antioxidant vitamins assessment: Vitamin A, C and E were determined chemically in accordance with method of Bassey et al., [16], Reo and Keuther [17] and Neil and Pierson [18] respectively.

Hematological indices: All hematological parameters were determined using automatic hematology analyzer (Sysmex).

\section{RESULTS}

All results were presented as Mean \pm Standard deviation.

Table-1: Distribution of antioxidant vitamins in pregnant women with and without pre-eclampsia

\begin{tabular}{|l|l|l|l|}
\hline PARAMETERS & PEW $(\mathbf{n}=\mathbf{7 7})$ & N.P.W $(\mathbf{n}=\mathbf{4 5})$ & Level of sig. \\
\hline B.P $(\mathbf{m m} / \mathbf{H g})$ & $153.2 \pm 3.6 / 99.7 \pm 4.4$ & $101.0 \pm 7.9 / 84.2 \pm 3.8$ & S.S \\
\hline Vitamin A $(\boldsymbol{\mu g} / \mathbf{d l})$ & $26.8 \pm 1.00$ & $39.6 \pm 1.20$ & S.S \\
\hline Vitamin C $(\mathbf{m g} / \mathbf{d l})$ & $0.44 \pm 0.05$ & $1.03 \pm 0.09$ & S.S \\
\hline Vitamin E(mg/dl) & $0.43 \pm 0.05$ & $1.23 \pm 0.23$ & S.S \\
\hline
\end{tabular}

KEY: PEW; BP=Blood pressure; PEW; Pre-eclamptic woman; NPW; Normotensive pregnant women; $n=$ number of subjects; $\mathrm{SS}=$ statistically significant.

Table-2: Body mass index and some hematological parameters of Pre-eclamptic and Healthy pregnant women

\begin{tabular}{|l|l|l|l|l|l|}
\hline & BMI $\left(\mathbf{k g} / \mathbf{m}^{2}\right)$ & PCV $(\%)$ & WBC(x10 $/ \mathbf{l})$ & Hb(g/dl) & PLT(x10\%/) \\
\hline PEW(n=77) & $32.8 \pm 0.95$ & $35.6 \pm 3.5$ & $7.3 \pm 0.22$ & $12.9 \pm 0.2$ & $229.2 \pm 4.0$ \\
\hline NPW(n=45) & $22.2 \pm 1.22$ & $35.9 \pm 2.7$ & $7.4 \pm 0.25$ & $12.6 \pm 0.4$ & $239.8 \pm 2.2$ \\
\hline Level of Sig. & S.S & N.S & N.S & N.S & S.S \\
\hline
\end{tabular}

KEY: PCV=Packed Cell Volume; WBC=White Blood Cells; Hb=Hemoglobin; BMI= Body Mass Index; PLT=Platelet; PEW=Pre-eclamptic woman; NPW; Normotensive pregnant women; $n=$ number of subjects; NS=Not significant.

Table-3: Percentage of antioxidant vitamins deficiencies in pre-eclampsia and normotensive subjects

\begin{tabular}{|l|l|l|}
\hline Parameters & Subjects & \\
\hline & Pre-eclamptic & Normotensive \\
\hline Vitamin A & $81 \%$ & $8 \%$ \\
\hline Vitamin C & $76 \%$ & $4 \%$ \\
\hline Vitamin E & $89 \%$ & $12 \%$ \\
\hline
\end{tabular}

*Values in table1.0 of the control mean were used as the reference.

\section{DISCUSSION}

There is no doubt that placenta favours the generation of reactive oxygen species due to exposure to high oxygen tension $[19,20]$. Results of current findings shows a statistical decreased $(p<0.005)$ of all the measured antioxidant vitamins in women with preeclampsia when compared to normotensive pregnant women. The vitamins depletion results from overwhelming usage by the body system in scavenging and delaying the deleterious effects of free radicals. Similarly, levels of oxidative modifications of protein, lipoprotein and antioxidants have been reported to be lower in women with pre-eclampsia [21, 22]. According to the results obtained, women with pre-eclampsia tend to have higher BMI and this may be one of the predisposing factors in the development of hypertension. This is also in line with the work performed by Pipkin [23], Sukonpan [24] and Akhtar [25]. Concentration of maternal hemoglobin revealed no statistical difference between pre-eclamptic and normotensive subjects (Table-2), Cordina et al., 26] reported no variation between the two groups, and however, this is in contrast with findings of Ceyhan et al., [27] which showed a decreased $\mathrm{Hb}$ concentration in pre-eclamptic subjects. The present study revealed low $(p<0.005)$ platelet count in pre-eclamptic subjects than in normotensive subjects. This is equally reported by Razia et al., [28].

\section{CONCLUSION}

In conclusion, reduced serum antioxidant vitamins and low platelet counts were observed in preeclamptic subjects compared to normotensive. High BMI is a predisposing factor associated with preeclampsia.

\section{RECOMMENDATION}

It is recommended that pregnant women undergo screening for pre-eclampsia before the second half of gestation, preferably preconceptionally. Supplementation of antioxidant vitamins should be given to all pregnant women at risk of pre eclampsia 
and platelet concentrate should be considered for preeclamptic patients.

Acknowledgements: Authors acknowledged the management of Rasheed Shekoni Specialist Hospital and General Hospital Dutse for their cooperation throughout the study period.

Conflict of interests: Authors declared that no conflict of interest exists

Funding: None

\section{REFERENCES}

1. Walker, J. J. (2000). Pre-eclampsia. Lancet, 356, 1260-126.

2. North, R. A., McCowan, L. M., Dekker, G. A., Poston L., Chan, E. H., \& Stewart, A. W. (2011). Clinical risk prediction for pre-eclampsia in nulliparous women: development of model in international prospective cohort. BMJ, 342:d1875

3. Mackay, A. P., Berg C. J., \& Atrash, H. K. (2001). Pregnancy-related mortality from preeclampsia and eclampsia. Obstet Gynecol. 97, 533-538.

4. Berg, C. J., Mackay A. P., Qin, C., \& Callaghan, W. M. (2009). Overview of maternal morbidity during hospitalization for labor and delivery in the United States: 1993-1997 and 2001-2005. Obstet \& Gynecol. 113, 1075-1081.

5. Schroeder, K. J., \& Dopke, J. L. (2002). U.S. Patent Application No. 29/142,269.

6. Roberts, J. M., \& Hubel, C. A. (2009). The two stage model of preeclampsia: variations on the theme. Placenta, 30Suppl. A, S32-S37.

7. Roberts J. M., Escudero C. (2012). The placenta in preeclampsia. Pregnancy Hypertens. 2, 72-83.

8. Kim-Shapiro, D. B., Schechter, A. N., \& Gladwin, M. T. (2006). Unravelingthe reactions of nitric oxide, nitrite, and hemoglobin in physiologyand therapeutics. Arterioscler Thromb Vasc Biol. 26, 697-705.

9. Redman, C. W., \& Sargent, I. L. (2008). Circulating microparticlesin normal pregnancy and pre-eclampsia. Placenta, 29, S73-S77.

10. Buonocore, G., Perrone, S., \& Tataranno M. L. (2010). Oxygen toxicity: chemistry and biology of reactive oxygen species. Semin. Fetal Neonatal Med. 15, 186-190.

11. Vanderlelie, J., Venardos, K., Clifton, V. L., Gude, N. M., Clarke, F. M., \& Perkins, A. V. (2005). Increased biological oxidation and reduced anti-oxidant enzyme activity in pre-eclamptic placentae. Placenta, 26, 53-58.

12. Rayman, M. P. (2009). Selenoproteins and human health: insights fromepidemiological data. Biochim Biophys Acta, 1790, 1533-1540.

13. Centlow, M., Carninci, P., Nemeth, K., Mezey, E., Brownstein, M., \& Hansson, S. R. (2008). Placental expression profiling in preeclampsia: local overproduction of hemoglobin may drive pathological changes. Fertil Steril. 90, 1834-1843.

14. Agarwal, A., Gupta, S., \& Sharma, R. K. (2005). Role of oxidative stress in female reproduction. Reproductive biology and endocrinology, 3(1), 28.

15. Raijimakers, M. T. M., Peters, W. H. M., Steegers, E. A. P., \& Poston, L. (2005). Amino thiols, detoxification and oxidative stress in preeclampsia and other disorders of pregnancy, Curr Pharmaceut Design, 11(6):711-734.

16. Bessey, O. A., Lowry, O. H., Brook, M. J., \& Lopez, J. A. (1964). Journal boilogy Chem: (3)166-17.

17. Reo, J. H., \& Kuether, C. A. (1943). Determination of ascorbic acid in whole blood and urine through the 2, 4-dinitrophenylhydrazine derivate of ascorbic acid. J Biochem, 143, 399. 406.

18. Neil, J. H., \& Pearson, C. A. (1907). Journal biology Chem; 165-169.

19. Casanueva E, Viteri FE. Iron and oxidative stress in pregnancy. The Journal of nutrition. 2003 May 1;133(5):1700S-8S.

20. Toescu, V., Nuttall, S. L., Martin, U., Nightingale, P., Kendall, M. J., Brydon, P., \& Dunne, F. (2004). Changes in plasma lipids and markers of oxidative stress in normal pregnancy and pregnancies complicated by diabetes. Clinical Science, 106(1), 93-98.

21. Hubel, C. A. (1999). Oxidative stress in the pathogenesis of preeclampsia. Proceedings of the Society for Experimental Biology and Medicine, 222(3), 222-235.

22. Raijmakers, M. T., Dechend, R., \& Poston, L. (2004). Oxidative stress and preeclampsia: rationale for antioxidant clinical trials. Hypertension, 44(4), 374-380.

23. Pipkin, F. B. Risk Factors for Pre-eclampsia. New England Journal Med. 2001;344:925-926.

24. Sukonpan, K., \& Phupong, V. (2005). Serum calcium and serum magnesium in normal and preeclamptic pregnancy. Archives of gynecology and obstetrics, 273(1), 12-16.

25. Akhtar, S., Begum, S., \& Ferdousi, S. (2011). Calcium and zinc deficiency in preeclamptic women. Journal of Bangladesh Society of Physiologist, 6(2), 94-99.

26. Cordina, R. L., Nakhla, S., O’Meagher, S., Leaney, J., Graham, S., \& Celermajer, D. S. (2015). Widespread endotheliopathy in adults with cyanotic congenital heart disease. Cardiology in the Young, 25(3), 511-519.

27. Aysan, A. F., \& Ceyhan, S. P. (2006). Why do foreign banks invest in Turkey?.

28. Razia, S. M., Fazlul, K., Farhana, A., Shabnila, F., \& Sedina, A. (2015). Platelet Count in Preeclampsia. Journal Dhaka National Med Coll Hos, 18(2):24-26. 